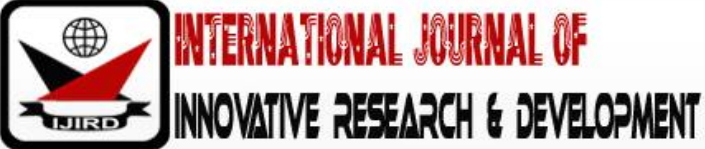

ISSN 2278 - 0211 (Online)

\section{The Effect of Mission Statement on Organisational Commitment of Selected Deposit Money Banks in Lagos State, Nigeria}

Onafowora, A.
Banker, Department of Business Administration and Marketing,
Babcock University, Illisan Remo, Ogun State, Nigerian
Dr. Makinde, G. 0.
Lecturer, Department of Business Administration and Marketing,
Babcock University, Illisan Remo, Ogun State, Nigeria
Dr. Akinlabi, B. H
Lecturer, Department of Business Administration and Marketing,
Babcock University, Illisan Remo, Ogun State, Nigeria

\begin{abstract}
:
The banking sector is an essential aspect of economic development. The performance of the sector in terms of commitment of employees has been declining due to lack of adequate strategic planning. Efforts have been put in place by managers of banks yet performance is still at a decline. This paper examined the effect of mission statement on organisational commitment in selected deposit money banks in Lagos state, Nigeria. The target population was 1,268 employees of selected deposit money banks in Lagos Nigeria. Cochran formula of 1997 was used to determine the sample size for the study and stratified sampling techniques was used to collect the samples for the study. A wellstructured and validated questionnaire was used collect the data for the study. Data was analyzed using descriptive and linear regression analysis. Results revealed that mission statement significantly affected employee commitment in the selected deposit money banks in Lagos state $\left(\beta=0.443, R^{2}=0.182, F=(1,414)=92.057, p<0.05\right)$. The paper concluded that mission statement significantly affects organisational commitment of the selected money deposit banks in Lagos state, Nigeria was. Sequel to finding of the study, it is recommended that Nigerian banks should reevaluate their vision and mission statements to include such activities that they are out to deliver. In doing this, employees' roles will be spelt out and they will know exactly what to do in the discharge of their duties in the banks
\end{abstract}

Keywords: Mission statement, organizational commitment, banking industry

\section{Introduction}

Globally the banking industry has for a long time been characterized with operational and structural inadequacies which gave rise to the need for several reforms over time. Hitherto, many banks according to the Global banking outlook survey (2018) various reports were associated with weak Board and Management oversight, nonperforming insiderrelated facilities, declining asset quality and attendant large-provisioning for bad debts, frauds attributable to weak internal control systems, over-dependence on public sector deposits, foreign exchange trading, dearth of skilled manpower and inadequate extension of credit to the real sector of the economy (GBO, 2018). The increasing wave of declining performance of financial institutions in recent years poses serious threats to the stability and survival of financial sector and banks in particular. Haneef (2017) opined that declined performance in the banking industry if not properly checked, might result in huge financial losses to banks and their customers, depletion of shareholders' funds and banks' capital base as well as loss of public confidence in banks. This low level of operational performance of the banking institutions do not correspond to what is depicted in many financial sectors in many countries which could lead to the closure of banks operations (Ohando, 2015).

In Nigeria and elsewhere in the world, different studies such as Jaja and Okpu (2013) and Jaja and Okpu (2014) have identified several organizational factors that could improve the commitment of workers in the banking institutions such as: performance (Oladejo, 2011, Zabid, 2003), monetary rewards (Omolayo \&Owolabi, 2007), psychological and demographic factors (Salami, 2008), structure (Ardrey, 2001), withdrawal intentions (Carmeli and Gefen, 2005), work family role (Akintayo, 2010), human resources management practice (Gbadamosi, 2003), as well as communication climate and job satisfaction Irrespective of these studies, there is still a problem of getting the commitment of workers, especially in Nigerian Organisations. Okpara (2004) discovered that Nigerian managers reported lower levels of commitment as compared to US managers. Other researchers have observed that Nigerian workers level of commitment is 
low (Aina, 2012; Ahiauzu \& Asawo, 2009). This commitment is low because they do not understand the mission and intent of the organisations that they work for. Sometimes there are no clear orientations and explanations in order to get then acquainted with the elements of the mission of the organisation.

There is a wide assumption of a strong linkage between mission statement and organisational performance. A review of the related literature (Lyles, 2014, Thompson \& Strickland 2016; Wheelen \& Hunger, 2015) have revealed that the research of mission statement and performance can be divided mainly into three aspects: the impact of existence and nonexistence of mission statement on performance, the content of mission statement, and the impact of mission statement components' on performance (Dermol, 2012).Generally speaking, studies show consistent results in terms of main components. In relation to the impact of mission statement on performance studies still show mixed results (Brown \& Yoshioka, 2016; Hope, Nkechi \& Ojiagu, 2015; Obasan \& Ogunkoya, 2013). While some of them show positive relationships, the others show negative relationships (O'Gorman \& Doran, 1999). Indeed, the literature has not presented adequate evidence to substantiate this assumption yet, and the relationship between mission statement and performance is still, unclear, and ambiguous (Bart \& Hupfer, 2004; Dermol, 2012; Desmidt, 2011). This has been attributed to the paucity of empirical studies between mission statements and performance as have been reported by several studies (Dermol, 2012; Desmidt, 2011; Williams, 2008). Specifically, this examines the effect of mission statement on organisational commitment in selected deposit money banks in Lagos state, Nigeria.

\section{Literature Review}

This section provides a detailed review of the variables used in this study, theories and the empirical findings of past studies.

\subsection{Mission Statement}

A company's strategic plan typically lays out its mission, vision and future direction, performance targets (objectives) and strategy (Thompson, 2014). For it to be effective therefore, Drucker (2010) emphasizes that strategic plans must be designed to support corporate mission, vision and objectives. A firm's mission according to Pitts (2013) describes the organisation in terms of the business it is in, the customers it serves and the skills it intends to develop to fulfill its vision. The mission statement describes organisational purpose; it addresses "Why we exist" (Grant, 2013). It presents the company's function, markets and competitive advantages, as well as it embodies a business's ambitions, goals and philosophies (Entrepreneur.com, 2015). The statement provides fundamental and necessary help to lead the company's strategies and actions by specifying the organisation's overall goal. A mission statement is the overriding and distinctive purpose of a company (Johnson, 2012; Pitts, 2013). Daft (2015) agrees it is the firm's reason for existence and Ritson (2016) affirms its linkage with vision.

Mission and vision are an important part not only of strategic management but also of a part of communication with the market because the companies present their organisational intentions to the stakeholders Ritson (2016). Vision and mission statements have been recognized as tools of strategic importance. According to Verna (2010), the content of these statements is important because of its influence on people's behavior and resource allocation. Literature on vision and mission statements (Mullane, 2002; Morphey and Hartley, 2006; Fox, 2006; Verna, 2010) demonstrates the value of vision and guiding principles: they help forming employee relationships between each other from the inside and the public and the stakeholders, especially with the customers from the outside.

Bart (2013) affirmed that Mission statement is designed to answer the most fundamental questions for every organisation: Why do we exist? What are we here for? What is our purpose? Strong (2016) averred that mission is the organisation's vision of its future position and how it will be achieved. Analoui and Karami (2012) averred that a mission statement allows the firm to articulate a strong vision for the organisation and to communicate that to its growing number of employees and professional managers. Desmidt (2011) claimed that mission statement is a formal document that articulates an organisation's distinct and enduring purpose.

\subsection{Organisational Commitment}

Organisational commitment has been variously conceptualized. To Meyer and Herscovitch, (2001), it is a psychological state that binds an employee to an organisation thereby reducing the problem of employee turnover and as a mind-set that takes different forms and binds an individual to a course of action that is of important to a particular target. Organisational commitment refers to a psychological state in which the employee shares the values of the organisation and adheres to its objectives (Paille, 2011).Meyer and Allen, (2001), defined commitment as a stabilizing force that acts to maintain behavioural direction when expectancy/equity conditions are not met and do not function. Commitment is an obliging force which requires that the person honour the commitment even in the face of fluctuating attitudes and whims (Brown, 2006). Sharma and Bajpai (2010) assert that employees are regarded as committed to an organisation if they willingly continue their association with the organisation and devote considerable effort to achieving Organisational goals. Organisational commitment has been divided into three categories: affective, continuance commitment and normative commitment. Affective commitment refers to the tendency of an employee to be psychologically attached to his/her employee owing to identification with the organisational objectives and goals. This is the type of commitment that makes an employee to be loyal to an organisation and also choose to remain loyal despite having options elsewhere (Eliyana, 2012).Affectively committed employees are seen as having a sense of belonging and identification that increases their involvement in the organisations activities, their willingness to pursue the organisation's goals, and their desire to remain with the organisation. 
Continuance commitment is when an employee weighs the cost of leaving the organisation. When the cost outweighs the benefits of leaving such an employee would rather choose to remain with the organisation. Continuance commitment describes an individual's need to remain with the organisation resulting from her/his recognition of the costs such as tenure, pay, benefits, vesting of pensions and family commitment associated with leaving the organisation. organisation as a way of paying back to the organisation that helped them to grow (Meyer \& Allen, 2010). Normative commitment reflects an individual's feeling of obligation to maintain organisational membership because he/she believes it is morally right to be loyal to, and stay in, the organisation. Although normative commitment is widely recognized as a salient dimension of organisational commitment, it has been found to be substantially interrelated with affective commitment (Coyle, 2008). Normative Commitment reflects a perceived obligation to remain in the organisation (Meyer, 2001).Normative commitment relaxes an employee' compulsory feelings towards collaborators or management; people stay because they think an obligation to perform (Ahmadi \& Avajian, 2011).

\subsection{Mission Statement and Organisational Commitment}

Research on mission and vision statements as strategic management tools has often been limited to private organisations and more so to the experience of senior executives and managers. William (2012) in his study reports the perspectives of employees of a unique public but profit-oriented tertiary institution with a renewed corporate mandate in a developing country. The results indicated that most employees have firsthand knowledge of the mission and vision statements though they do not frequently come across them; Also, the level of knowledge of the components/contents and perceptions about ownership are low. Employees see ownership as a prerequisite for the statements to impact on their behaviors and attitudes.

Varsha and Monika (2012) findings reveal that there exists positive relationship between the three commitmentsaffective, continuance and normative commitment and sustained productivity of the organisation. It has also been proved from the results that there exists high degree of correlation between the three independent variables and sustained productivity the dependent variable. These outcomes in turn are associated with guiding the top management for working towards increasing commitment level. We have a big pool of employees employed by the auto-component industry. Due to higher quality consciousness and increased competitiveness the concept of sustained productivity becomes important. From the findings it has been proved that sustained productivity is strongly related to employees' commitment. Omolayo and Owolabi (2007) found that no significant difference exists in the commitment level of more tenured and less tenured employees in monetary reward. Equally, no significant difference was found in the commitment level of male and female employees in term of monetary reward. Result also revealed that high educated employees have no significant difference in their commitment level with that of low educated employees.

In terms of mission and vision within the literature, one of the contradictions found lies between the studies of Bart (2011) and of Sufi \& Lyons (2013). Bart (2001) conducted a study aiming to find out if there is a connection between mission statement and a well-defined organisational commitment. The results indicated that the mission statement can have a positive influence on the organisational commitment of a company. However, in the study conducted by Sufi and Lyons (2013) within the hospitality sector, no relationship could be found between the mission statement and the organisational commitment of a company. That brings up the question of how these researchers are able to define what a good mission statement is when there is no real consensus on the definition and the formulation of such a statement. The study therefore hypothesized that:

- $\mathrm{H}_{0}$ : Mission statement does not significantly affect organisational commitment of the selected deposit money banks in Lagos state, Nigeria.

This study adopted Resources-Based View (RBV) and dynamic capabilities theory as baseline theories for this study. These theories are selected to guide this study because their perspectives are tied to the focus of the study and the variables under investigation. Thus, the Resources-Based View (RBV) is deemed suitable in studying the effect of strategic planning on organisational performance among selected deposit money banks in Lagos, Nigeria. Augier and Teece (2009) suggested that dynamic capabilities have a tripartite structure: the capability to sense opportunities; the capacity to seize opportunities; and the capacity to manage threats through combination, recombination and reconfiguration of assets inside and outside the enterprise's boundaries which informed this research. With dynamic capabilities, sustained operational performance comes from the firm's ability to leverage and reconfigure its existing competencies and assets in ways that are valuable to the customer but difficult for other competitors to imitate. Dynamic capabilities help firm's sense opportunities and then seize them by successfully reallocating resources, often by adjusting existing competencies or developing new ones.Dynamic capabilities extend the RBV by examining the sources of competitive advantage in rapidly changing markets, and refer to firms' abilities to 'integrate, build, and reconfigure internal and external competencies to address rapidly changing environments' (Teece, Pisano \& Shuen, 1997).

\section{Research Methodology}

The research design adopted for this study was cross-sectional survey research design. This study is focused on 1368top, senior and middle staff of five-selected money deposit bank employees. The data was collected from the survey of 416 respondents out of 499 questionnaires given out to employees of First Bank of Nigeria, Guaranty Trust bank, Zenith Bank, Access Bank and United Bank for Africa. The study used a quantitative technique. The SPSS was used to present and analyze the data. Six (6) point Likert was used in the design of questionnaires: very high (6) to very low (1). 


\section{Data Analysis and Hypothesis Test}

\subsection{Test of Hypothesis}

In the course of this research work, a hypothesis was tested. Findings and conclusion from the analyzed data are tested at 0.05 significance level.

- $\mathrm{Ho}_{1}$ : Mission statement does not significantly affect organisational commitment of the selected money deposit banks in Lagos state, Nigeria.

The summary of the linear regression analysis of the hypothesis is presented below.

\begin{tabular}{|c|c|c|c|c|c|c|}
\hline \multicolumn{9}{|c|}{ Coefficientsa } \\
\hline \multicolumn{2}{|c|}{ Model } & Unstandardized Coefficients & Standardized Coefficients & \multirow{2}{*}{ S } & \multirow{2}{*}{ Sig. } \\
\cline { 3 - 7 } \multicolumn{2}{|c|}{} & B & Std. Error & Beta & & \\
\hline \multirow{2}{*}{1} & (Constant) & 13.907 & 1.212 & & 11.475 & 0.000 \\
\cline { 2 - 7 } & Mission Statement & 0.443 & 0.046 & 0.427 & 0.000 \\
\hline
\end{tabular}

Table 1: Linear Regression Analysis of Mission Statement on Organisational Commitment

$$
\begin{gathered}
\text { a. Dependent Variable: Organizational Commitment } \\
R=0.427, R 2=0.182, F=(1,414)=92.057, p<0.05 \\
* \text { Results Is Significant at the 0.05 Level }
\end{gathered}
$$

As evidenced in Table 1, mission statement has a significant effect on organisational $\operatorname{commitment}(\beta=0.443, R=$ $\left.0.427, R^{2}=0.182, F(1,414)=92.057, \mathrm{p}<0.05\right)$. The $\beta=0.433$ shows that a unit increase in mission statement leads to 0.443 units improvement or change in organisational commitment of the selected deposit money banks in Lagos state. The $\mathrm{R}=$ 0.427 shows the level at which the relationship between mission statement and organisational commitment can be measured. By this the result shows that a $42.7 \%$ moderate relationship exists between mission statement and organisational commitment. This implies that as the mission statement of the organisation is being improved, it leads to a proportionate rise or increase of 42.7 units in organisational commitment. The $\mathrm{R}^{2}$ which is referred to as coefficient of determination is given as 0.182 . This signifies that the effect of mission statement on organisational commitment is given as $18.2 \%$. The implication here is that $18.2 \%$ of the changes or variation in organisational commitment can be accounted for by mission state. From the unstandardized coefficients, the regression model can be extracted which help to form the line of best will fit for the analysis.From the results the p value obtained is $(0.000)$ less than the conventional $p$-value (0.05) used in the study. Therefore, the null hypothesis which state that Mission statement does not significantly affect organisational commitment of the selected money deposit banks in Lagos state, Nigeria was rejected.

\subsection{Discussion}

The results of the study revealed that mission statement has a significant effect on organisational commitment of selected deposit money banks in Lagos state. In line with the result, William (2012) in his paper reports the perspectives of employees of a unique public but profit-oriented tertiary institution with a renewed corporate. The results indicated that most employees have firsthand knowledge of the mission and vision statements though they do not frequently come across them; Also, the level of knowledge of the components/contents and perceptions about ownership are low. Employees see ownership as a prerequisite for the statements to impact on their behaviors and attitudes. In furtherance of these arguments, mission statements are said to do a good job in capturing corporate level strategy in terms of scope, boundaries and value creation (Johnson, 2008; David; 1993). Mission statements have been reported as a broad overarching framework around which other strategic concerns like vision, strategic intent and capabilities, goals, objectives, core values, behavioral standards, business models etc., evolve (Campbell and Tawadey, 1992; Lynch, 2000).

In Varsha and Monika (2012), the business organisations are aware of the importance of organisational commitment and its role in motivating employees. The purpose of this study was to identify the impact of employees' commitment on sustained productivity in Auto-component Industry in India (Denso). The results of the study indicate that the Employees Commitment (Affective, Normative, continuous) are significantly related to sustain sustained productivity in Auto component industry. The research findings reveal that there exists positive relationship between the three commitments- affective, continuance and normative commitment and sustained productivity of the organisation. It has also been proved from the results that there exists high degree of correlation between the three independent variables and sustained productivity the dependent variable. These outcomes in turn are associated with guiding the top management for working towards increasing commitment level. We have a big pool of employees employed by the autocomponent industry. Due to higher quality consciousness and increased competitiveness the concept of sustained productivity becomes important. From the findings it has been proved that sustained productivity is strongly related to employees' commitment.

\section{Conclusion and Recommendation}

The study concluded that mission statement significantly affects organisational commitment of the selected money deposit banks in Lagos state, Nigeria. Based on this conclusion, there is need for Nigerian banks to reevaluate their vision and mission statements to include such activities that they are out to deliver. In doing this, employees' roles will be spelt out and they will know exactly what to do in the discharge of their duties in the banks. This will help to their commitment level to the job because they will see that they are a critical part of the overall intent, strategies, and processes of the firm. As such future study should be extended different variables that are related to strategic plaining and 
organisational performance should be used. Also, the context of the study can be changed in order to have a divergent outlook on the study.

\section{References}

i. Ahiauzu A, Asawo SP (2009). Altruistic love culture and workers' commitment in the Nigerian manufacturing industry, a study in workplace spirituality. In Sigue S. (ed), Repositioning African Business and Development for the 21st Century, A paper presented on the proceedings of the 10th Annual Conference IAABD, Kampala, Uganda, 351-358.

ii. Aina S, (2012). Organisation culture and employee's commitment in public tertiary institutions in Lagos State. Nigeria Europe Journal of Globalization Development. 3(1), 127-142.

iii. Akintayo, D. I. (2010). Work-family role conflict and organisational commitment among industrial workers in Nigeria. International Journal of Psychology and Counselling, 2(1), 1-8.

iv. Bart, CK (2013), 'Measuring the mission effect in human intellectual capital', Journal of Intellectual Capital, 3(2), 320-330.

v. Brown, W. A. (2006). Impact of organisational commitment on organisational performance. Arabian Journal of Business and Management Review, 3(1), 71- 87.

vi. Dalia A. a. (2011). Losing your best talent: Employee retention the dilemma of textile industry.

vii. Daniel, J. (2011). Ranking of system implementation success factors. Project Management Journal, 27(6), 4953.

viii. $\quad$ Dermol, V. (2012). Identifying the Mission Statement's Clusters in Slovenian Economy. TIIM 2012, Lublin, Poland.

ix. Dermol, V. (2012). Identifying the Mission Statement's Clusters in Slovenian Economy. TIIM 2012, Lublin, Poland.

X. Desai, M. (2012). Manufacturing strategy, competitive strategy and firm performance: An empirical study in a developing economy environment. International Journal of $\quad$ Production Economics, 11(2), 575-592.

xi. Desmidt C., (2011). CEO Succession: Some finer and perhaps provocative points. Journal of Business Strategy, 28(3), 6-18.

xii. Gbadamosi, G (2003). HRM and the commitment rhetoric: Challenges for Africa. Management Decision, 41(3), 274-280.

xiii. Global banking outlook (2018). Pivoting toward an innovation-led strategy.

xiv. Haneef, S (2017) Impact of Risk management on non-performing loans and profitability of banking sector of Pakistan. International Journal of Business and Social Science, 3 (7), 99-44

xv. Hope, N; Nkechi, T \& Ojiagu, A.O. (2015). Industrial policy on fish farming and sustainable economic growth in Nigeria (1990-2016). Saudi Journal of Business and Management Studies. 2(5), 33-49

xvi. Jaja, S.A and Okpu, T (2013). Suggestion scheme and workers commitment in Nigerian banking industry. International Journal of Engineering and Science, 2(11), 43-51.

a. New York: Economist.

xvii. Obasan K, Ogunkoya A. (2013). Strategic planning and bank management in Nigeria: Issues for consideration. Journal of Research and Development, 1(2) 4-7.

xviii. Ohando R.0 (2015). Relationship between fraud risk management practices and financial performance of commercial banks in Kenya. University of Nairobi Research Archives.

xix. Oladejo M.A, (2011). Job related factors, leadership, motivation and career commitment in a Nigerian college of education. Journal of Business Economics, 1 (1): 41-58

xx. Omolayo H P \& Owolabi, D. (2007). The balanced scorecard: The measures that drive performance. Harvard Business Review, 8(3), 71-79.

xxi. Thompson E P \& Strickland, L., (2012). Managing strategy Implementation: An Organizational Behaviour Perspective. Oxford: Blackwell.

xxii. Thompson, K. (2014). A review of approaches to empirical research on the resource-based view of the firm. Journal of Management, 33(6), 959-986.

xxiii. Thompson, P. (2017). Applied Multiple Regression/Correlation:Analysis for the Behavioral Sciences (2nd Ed). Hillsdale, NJ: Lawrence Erlbaum.

xxiv. Weick S. (1991). Defining the socially responsible Leader. The Leadership Quarterly, 7(2), 17-35.

xxv. Wernerfelt, K. M. (1984). Factors affecting employees' organisational commitment: A study of banking staff in Ho Chi Minh city, Vietnam. Journal of Advanced Management Science, $\quad 2$ (1), 1-3.

xxvi. Wheelen O. K \& Hunger, T.M (2016). Structural inertia and organisation change. American Sociological Review, 49 (2), 149-164

xxvii. William, M., (2016). Does strategic planning enhance or impede innovation and firm performance.Journal of Product Innovation Management, 28(4), 503-520.

xxviii. Zabid, M (2003). The influence of corporate culture and organisational commitment on performance. Journal of Management Development, 22(8), 708-728. 